\title{
Effectiveness of Subgingival Irrigation with Irrigation Device and Conventional Syringe Irrigation in the Teeth Indicated For Extraction
}

\author{
Dr. Aswani Cherukuri ${ }^{1 *}$, Dr. Prabhuji MLV ${ }^{2}$ \\ ${ }^{I}$ Post graduate, Department of Periodontology, Krishnadevaraya College of Dental Sciences and Hospital, \\ Bangalore- 562157, Karnataka, India. \\ ${ }^{2}$ Head of the Department, Department of Periodontology, Krishnadevaraya College of Dental Sciences and \\ Hospital, Bangalore- 562157, Karnataka, India.
}

*Corresponding Author: Dr. Aswani Cherukuri, Post graduate, Department of Periodontology, Krishnadevaraya College of Dental Sciences and Hospital, Bangalore- 562157, Karnataka, India.

\begin{abstract}
The effectiveness of conventional scaling and root planing may be augmented by application of local or systemic antibiotics. one of the ways by which local antibiotic therapy is being administered is through irrigation. It has been clinically proven to optimise the outcome of scaling and root planing. The current case report was aimed at comparing the effectiveness of an intra-canal irrigation device to that of normal syringe irrigation for assessing the depth of penetration of irrigation solution into the pocket following scaling and root planing.
\end{abstract}

Keywords: Pocket, Periodontitis, Subgingival Irrigation, Endovac, Extraction

\section{INTRODUCTION}

Mechanical periodontal therapy of plaque removal, scaling and root planing following subgingival irrigation has shown to reduce dental plaque, gingivitis and pathogens causing periodontal disease. Methods to augment the positive effects of scaling and root planing on the periodontium include periodic maintenance therapy that may be combined with both systemic or topical antibiotics, and intrapocket irrigations with a variety of antimicrobial agents. [1, 2] Systemic administration of antimicrobial agents cannot be the chosen in all the patients owing to the indications of usage and to prevent antibiotic resistance. Subgingival irrigation makes use of a syringe loaded with an irrigating solution. However, this cannot reach narrow areas like the base of periodontal pockets. Also, it may lead to unwanted trauma to the tissues. Also, there exists proven evidence that oral irrigation devices had shown a significant increase of penetration of about $71 \%$ into the pocket than $44 \%$ with the conventional method. [3]

The current study was aimed at comparing the effectiveness of an intra-canal irrigation device to that of normal syringe irrigation for assessing the depth of penetration of irrigation solution into the pocket following scaling and root planing.

\section{MeThodology}

Patients who had one or more teeth indicated for extraction due to dento-alveolar abscess or poor prognosis tooth with periodontal bone loss extending till the apical third of the root and with grade III mobility were selected for the study. All the patients recruited were not under active periodontal therapy. A total of 8 samples pertaining to the inclusion criteria were considered.

Intracanal irrigation devices are used in endodontic therapy for root canal irrigation. It consists of a multiport adapter which is connected to the suction unit of the dental chair, with a macrocannula which is loaded with irrigation solution (Figure 1 and 2). In the control group, subgingival irrigation with normal syringe containing disclosing solution was done and in the test group, subgingival irrigation with disclosing solution using intracanal irrigation device $\left(\right.$ Endovac $\left.^{\mathrm{TM}}\right)$ was done (Figure 4). Prior to the procedure the pocket 
depth was assessed (Figure 5). The endovac system including the macrocanulla is connected to the suction unit (Figure 6 and 7). After irrigation, local anaesthesia was administered and the teeth were extracted later. The depth of penetration (DP) of dye into the pocket was measured by subtracting the crown height from the distance between a reference notch on the crown (prepared before extraction) to the apical extent dyed (Figure 7 and 8).

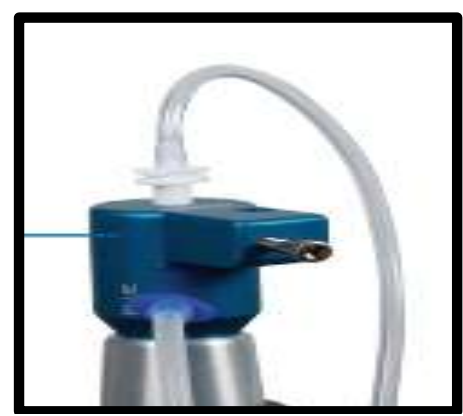

Figure 1. Multiport adaptor that is connected to the suction unit of the dental chair

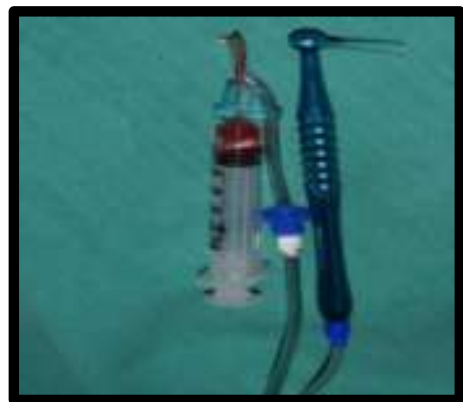

Figure 2. Delivery tip \& macrocannula

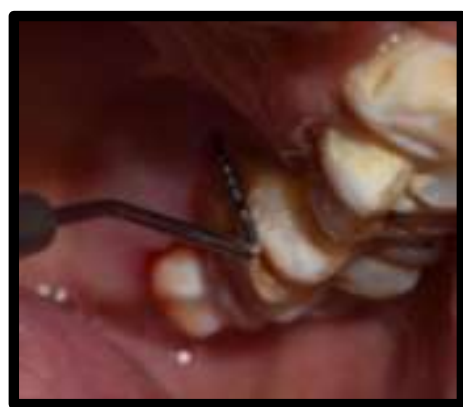

Figure 3. Measurement of pocket depth

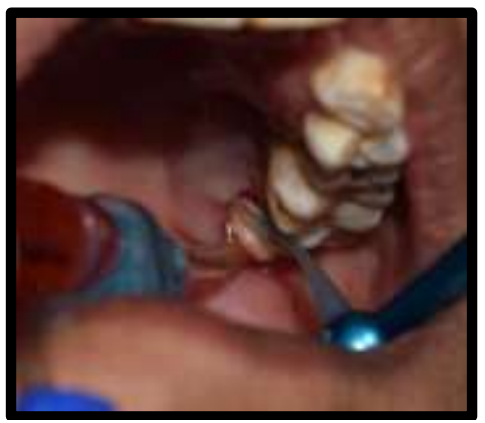

Figure 4. Intracanal irrigation (Endovac ${ }^{T M}$ )

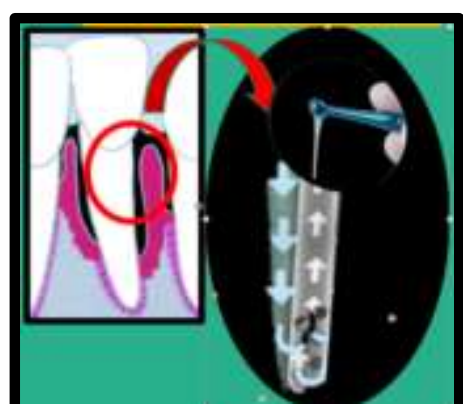

Figure 5. Endovac system

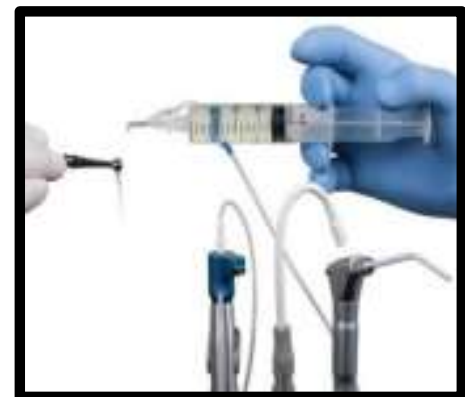

Figure 6. Macro cannula connected to the suction

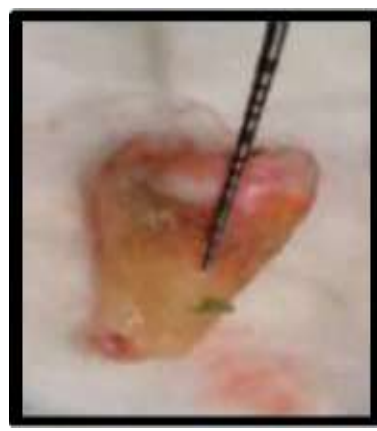

Figure 7. Depth of penetration of the dye irrigation syringe

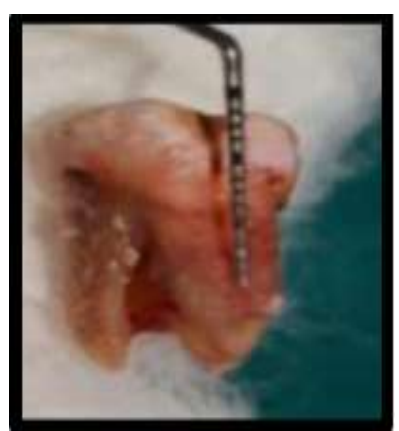

Figure 8. Depth of penetration in conventional (intracanal irrigation)

\section{Results}

In the current study, subgingival irrigation using an intracanal irrigation device and conventional irrigation syringe had given similar results (Table 1 and 2). However, there was a better depth of penetration of about $2 / 3^{\text {rd }}$ the length of root with the irrigation device compared to the irrigation syringe. 
Effectiveness of Subgingival Irrigation with Irrigation Device and Conventional Syringe Irrigation in the Teeth Indicated For Extraction

Table 1. Depth of penetration of the dye in control group

\begin{tabular}{|l|l|l|l|l|}
\hline CONTROL GROUP & Tooth 1 & Tooth 2 & Tooth 3 & Tooth 4 \\
\hline Pocket depth (PD) & $7 \mathrm{~mm}$ & $8 \mathrm{~mm}$ & $9 \mathrm{~mm}$ & $8 \mathrm{~mm}$ \\
\hline Depth of penetration of dye in millimeters (mm) & $3 \mathrm{~mm}$ & $2 \mathrm{~mm}$ & $3 \mathrm{~mm}$ & $4 \mathrm{~mm}$ \\
\hline
\end{tabular}

Table 2. Depth of penetration of the dye in test group

\begin{tabular}{|l|l|l|l|l|}
\hline TEST GROUP & Tooth 1 & Tooth 2 & Tooth 3 & Tooth 4 \\
\hline Pocket depth (PD) & $8 \mathrm{~mm}$ & $7 \mathrm{~mm}$ & $10 \mathrm{~mm}$ & $8 \mathrm{~mm}$ \\
\hline Depth of penetration of dye in millimeters (mm) & $5 \mathrm{~mm}$ & $4 \mathrm{~mm}$ & $7 \mathrm{~mm}$ & $5 \mathrm{~mm}$ \\
\hline
\end{tabular}

\section{DISCUSSION}

The intracanal irrigation device is used for the irrigation of root canals during endodontic therapy. [4] The periodontal pockets $>5-7 \mathrm{~mm}$ always pose a challenge for the clinician during routine scaling and root planing procedures to reach the base of the pocket. Hence, there is a need for periodontal pockets to be thoroughly irrigated post scaling and root planning to eliminate any debris from the mechanical therapy and also to flush out the pocket contents to cease the progression of disease activity.

This irrigation device has a syringe in which the irrigating solution is loaded for irrigation and a macro cannula connected to the suction unit of the dental chair to be inserted into the periodontal pocket base. This macro-cannula creates a negative pressure at the base of the pocket causing the irrigation solution to be carried till the pocket base from where it is suctioned out. This produces an effective depth of penetration of the irrigation solution.

Various other irrigation devices had been employed for oral irrigation showing a better depth of penetration. [5] The outcome of this intracanal irrigation device when used for subgingival irrigation needs to be compared with other oral irrigation devices before claiming its significance. Also, this was assessed on an extracted tooth where the outcome of the subgingival irrigation in terms of inflammation reduction that cannot be predicted.

\section{CONCLUSION}

This case report demonstrated an intracanal irrigation system used for periodontal intra pocket irrigation. It was observed that compared to conventional irrigating syringes, the Endovac $^{\mathrm{TM}}$ system showed superior depth of penetration of the irrigating solution indicating its efficiency in deeper pockets. Employing this technique in moderate to generalized periodontitis patients following non-surgical therapy would give a better scope to assess the effectiveness of the technique.

\section{REFERENCES}

[1] Newman MG, Takei H, Klokkevold PR, Carranza FA. Carranza's clinical periodontology. Elsevier health sciences; 2011 Feb 14.

[2] Quirynen M, Teughels W, Van Steenberghe D. Microbial shifts after subgingival debridement and formation of bacterial resistance when combined with local or systemic antimicrobials. Oral diseases. 2003 Jun;9:30-7.

[3] Braun RE, Ciancio SG. Subgingival delivery by an oral irrigation device. Journal of periodontology. 1992 May;63(5):469-72.

[4] Siu C, Baumgartner JC. Comparison of the debridement efficacy of the EndoVac irrigation system and conventional needle root canal irrigation in vivo. Journal of Endodontics. 2010 Nov 1;36(11):1782-5.

[5] Itic J, Serfaty R. Clinical effectiveness of subgingival irrigation with a pulsated jet irrigator versus syringe. Journal of periodontology. 1992 Mar;63(3):174-81.

Citation: Dr. Aswani Cherukuri, Dr. Prabhuji MLV. Effectiveness of Subgingival Irrigation with Irrigation Device and Conventional Syringe Irrigation in the Teeth Indicated For Extraction. ARC Journal of Dental science. 2020; 5(1):8-10. doi:dx.doi.org/10.20431/2456-0030.0501003.

Copyright: (C) 2020 Authors. This is an open-access article distributed under the terms of the Creative Commons Attribution License, which permits unrestricted use, distribution, and reproduction in any medium, provided the original author and source are credited. 